\title{
РОЛЬ ФОНДОВОГО РЫНКА В ФИНАНСИРОВАНИИ ЭКОНОМИКИ РФ
}

\author{
(c) 2019 Михайлов Александр Михайлович \\ доктор экономических наук, профессор \\ Самарский государственный экономический университет, Россия, Самара \\ E-mail: 2427994@mail.ru \\ (c) 2019 Искандаров Тимур Сирачович \\ Самарский государственный экономический университет, Россия, Самара \\ E-mail: iskandarov@mail.ru \\ (c) 2019 Городнов Валерий Андреевич \\ Самарский государственный экономический университет, Россия, Самара \\ E-mail: gorodnowalera@yandex.ru
}

В статье проведен анализ фондового рынка России с позиций его роли в финансировании экономики. Для того чтобы ответить на данный вопрос использованы данные, которые были предложены зарубежными авторами. Проведенный анализ показал, что в роль фондового рынка в финансовой системе России повышается. Рассмотрен комплекс мер необходимых для дальнейшего развития фондового рынка России.

Ключевые слова: фондовый рынок, финансирование экономики, налогообложение финансовых операций, коллективные инвестиции, корпоративное управление, управление на финансовых рынках.

Во развитых экономиках мира важной составляющей является фондовый рынок, который также как и банковский сектор является инструментом перераспределения денежных средств от агентов, которые имеют свободные средства, к агентам, которые нуждаются в дополнительном финансировании [6]. Для каждой финансовой системы основополагающим фактором является то, насколько банковский сектор и фондовый рынок вовлечен в процесс финансирования инвестиционной активности компаний. Развитие фондового рынка увеличивает степень участия предприятий в процесс привлечения дополнительных денежных средств для своих инвестиционных программ посредством размещения ценных бумаг на фондовом рынке [5]. Хорошо развитый фондовый рынок может играть ведущую роль в финансировании экономики в сравнении с банковским сектором. Если фондовый рынок в стране развит плохо, то возможны ситуации, при которых предприятиям не хватает средств для финансирования. Следствием будет замедление увеличения рабочих мест, снижение производства продукции и производительности труда, что в свою очередь приведет к снижению реальных доходов населения и, в итоге, к снижению спроса в экономике. Результатом вышеизложенного может стать положение, когда эконо- мика страны начнет стагнировать.

Говоря о роли фондового рынка для страны, необходимо также упомянуть факт, что развитый фондовый рынок содействует притоку иностранных инвестиций в экономику, что является крайне важным для стран, где потребность в инвестиционных средствах выше, чем величина создаваемых ими сбережений [9]. Для примера рассмотрим Россию. Невзирая на развивающуюся экономику с высокой доходностью, проблема недостатка долгосрочных инвестиций до сих пор не решена, так как многие иностранные инвесторы больше склонны к портфельным инвестициям, а не к прямым. Следует понимать, что для привлечения иностранного капитала в нашу экономику, в первую очередь нужно провести ряд структурных изменений на фондовом рынке [7].

В России достаточно развит банковский сектор, значимость же фондового рынка в финансировании экономики страны пока еще не настолько высока. Минус плохого развития фондового рынка состоит в том, что небольшим предприятиям с высокотехнологичным или просто неординарным продуктом сложно взять кредит в банке, потому что у них нет больших материальных активов для залога, а банк не оценивает будущий потенциал роста компании. 
При этом стоит отметить, что в России все же работают фондовые площадки для предприятий с небольшой рыночной стоимостью. Первой такой площадкой была RTS start, открывшаяся на PTC в 2007 г. Её основали для предприятий с небольшой и средней капитализации, у которых не было возможности для выхода на главную площадку РТС. За первый год существования данной площадки на ней было проведено 5 выпусков акций предприятий из разных отраслей экономики. Как бы то ни было, с момента объединения бирж и создания Московской биржи данная площадка перестала осуществлять свою деятельность.

В июле 2009 года была основана аналогичная площадка на ММВБ, которая получила название - сектор инновационных и растущих компаний (ИРК). Она была основана, в основном для высокотехнологичных компаний из таких отраслей, как разработка ПО, интернет, телекоммуникации, электроника и биотехнологии. Для того чтобы попасть на эту площадку необходимо было соответствовать следующим критериям:

1. Капитализация компании должна быть не менее 500 млн. рублей.

2. Нужно обязательно соответствовать одному из следующих критериев:

- компания должна осуществлять производство продукции, оказывать услуги, производить или применять технологии, которые входят в перечень приоритетных направлений развития технологий, науки и техники в России, или же в перечень критических технологий России (УП РФ от 07.07.2011 N899);

- компания должна осуществлять производство продукции, оказывать услуги, производить или применять технологии, которые включены в Реестр инновационных технологий, продуктов и услуг, которые рекомендуются к использованию в России;

- компания должна осуществлять инвестирование в высокотехнологичные и инновационные предприятия и проекты наноиндустрии; Предприятия получало финансирование или иную помощь со стороны одной из следующих организаций: АО «РВК», Фонда «ВЭБ Инновации», АО «РОСНАНО», Российского фонда технологического развития, Фонда содействия развитию малых форм предприятий в научно-технической сфере, Фонда «Сколково», Фонда Развития Интернет-Инициатив;

- компания должна входить в реестр аккре- дитованных предприятий, которые осуществляют свою деятельность в области IT, раскрытие которого осуществляется на сайте Министерства связи и массовых коммуникаций России в сети Интернет;

- компания должна осуществлять хозяйственную деятельность с помощью применения инновационных подходов и технологий.

Эмитент должен предоставлять инвестиционный меморандум - документ, который описывает главные направления развития бизнеса компании, а также финансовые показатели. Надо отметить, что предприятия не с высокотехнологичными продуктами также могли размещать свои ценные бумаги на данной площадке.

После объединения бирж данная площадка продолжила свою работу, но под другим названием - «Рынок инноваций и инвестиций Московской биржи» (РИИ). По данным на декабрь 2017 года на этой площадке были в обращении акции 52 предприятий. Также кроме РИИ на Московской бирже работает РИИ 2. Её создали для того чтобы и маленькие предприятия имели возможность привлекать финансирование.

Работа представленных площадок, поддерживает предприятия с маленькой капитализацией, которые занимаются высокими технологиями и желают получить финансирование на фондовом рынке. Это хороший опыт для последующего становления рынка.

Российский фондовый рынок в настоящее время сильно монополизирован, многие отрасли, например строительная и нефтегазовая, недоступны для конкуренции вследствие того, что процесс образования цены в данных отраслях далеко не рыночный и конкуренция как таковая там отсутствует. У предприятий просто нет потенциала для выхода на такие рынки. Для дальнейшего развития рыночной экономики в России нужно развитие фондового рынка. Оживление фондового рынка в России начинается тогда, когда инвесторы могут доверять предприятиям, партнерам, банкам, государству, чему будет содействовать решение проблем ликвидности и притока иностранных денежных средств [2].

Для благополучного роста фондового рынка в России требуется провести комплекс мер, включающий в себя:

1. Развитие законодательства. При этом повышенное внимание следует уделить налоговому законодательству, поскольку оно в на- 
стоящее время часто пренебрегает спецификой налогообложения некоторых видов финансовых операций его нормы в отношении финансового рынка России не всегда сходятся с аналогичными понятиями и терминами, закрепленными в гражданском кодексе и в законодательстве в сфере РЦБ. В результате возникают проблемы спорности толкования некоторых норм и правил в законодательстве. Нередко режим налогообложения на финансовом рынке России более жесткий, чем в других мировых финансовых центрах. В настоящее момент есть объективная необходимость в принятии мер, которые увеличили бы привлекательность налогообложения на российском финансовом рынке. Это даст возможность конкурировать с мировыми финансовыми центрами.

2. Уменьшение количества административных преград и упрощение процедур. В последнее время ФСФР РФ приняла определенные меры, упростившие процедуры государственной регистрации выпусков ЦБ, что стало одной из главных причин роста объемов операций с ценными бумагами на фондовом рынке России. В тоже время следует отметить, что данная работа еще не закончена. Вдобавок необходимо облегчить процесс выпуска ценных бумаг, которые преобразуются в другие ценные бумаги, имеющие тот же объем прав и ту же долю акционеров.

3. Становления срочного рынка и рынка коллективных инвестиций. В настоящее момент ФСФР РФ разработала проект и положение соответствующего нормативного акта. Некоторый перечень проблем срочного рынка в России вызван сегментированием его управления по базовому активу и отсутствием единого государственного органа, задачей которого было бы регулирование, надзор и контроль. С помощью создания и утверждения нормативно правовых актов нужно утвердить меры, направленные на увеличении круга финансовых инструментов для инвестирования денежных средств институтов коллективных инвестиций, которые включают иностранные ценные бумаги. Возникновение новых типов инвестиционных фондов, ориентированных на инвестирование в области экономики, является важнейшим направлением. Необходимо модернизация контроля за безопасностью денежных средств коллективного инвестирования со стороны специализированного депозитария, введение системы для управления рисками при заключении срочных сделок ин- ститутами коллективного инвестирования.

4. Улучшение качества корпоративного управления. В последнее время в России принято большое количество мер по обеспечению нужного качества корпоративного управления. Тем не менее, есть ряд проблем, требующих решения, как в краткосрочной, так и в долгосрочной перспективе. Необходимо устранить несоответствие норм в разных нормативно правовых актах, касающихся ответственности руководителей обществ, вдобавок нужно уточнить процессуальный статус акционера, предъявляющего иск в интересах общества.

5. Совершенствование механизмов привлечения инвесторов и механизмов охраны их интересов. Безостановочная и компетентная работа населения на финансовых рынках является одним из причин, которые определяют не только уровень жизни в стране, но и показывают стадию развитости финансового рынка, обеспечивающего превращение личных сбережений людей в нужные для экономики инвестиции. Последние в свою очередь говорит о росте грамотности населения, о понимании им основных принципов работы фондовых рынков. Управление этой областью со стороны государства необходимо направить на усиление элементов осознанного поведения розничных инвесторов, их безопасность, формирование условий для уменьшения рисков индивидуальных инвестиций, исключение спонтанности, опрометчивого риска и азарта, которые обычно сопутствуют первым стадиям развития рынка ценных бумаг и инвестиционной активности людей [4]. Увеличение интереса граждан к финансовому рынку и поощрение инвестирования на нем индивидуальных сбережений происходит за счет целого ряда мер. Одним из главных средств поощрения участия инвесторов на финансовых рынках могут стать компенсация и страховка.

6. Улучшение управления на финансовых рынках. Улучшение управления на финансовом рынке необходимо осуществлять по трем важным направлениям:

- во-первых, увеличение роли саморегулируемых организаций и налаживания их более тесного сотрудничества с государственным регулятором финансового рынка;

- во-вторых, стандартизация правил и норм государственного управления финансовым рынком с поэтапным сосредоточением государственных функций по управлению, надзору и 
контролю на финансовом рынке в одном государственном органе;

- в-третьих, совершенствование системы пруденциального надзора;

7. Предупреждение и предотвращение злостной деятельности. Пресечение манипуляции ценами и заключения сделок на основе нераскрытой информации. Чрезвычайно насущной остается задача принятие закона о препятствовании злоупотреблениям на товарных и финансовых рынках. Упомянутый законопроект подготовлен ФСФР РФ и согласован с заинтересованными органами исполнительной власти. Одновременно с этим, одобрение закона нуждается не только в отдельных юридических уточнениях редакции его положений, но и более публичной и широкой работы по организации этики и правил поведения членов рынка ценных бумаг, исключающих возможности манипуляции ценами, применения нераскрытой информации. Некоторые меры по устранению перечисленных злоупотреблений на организованном рынке могут быть приняты безотлагательно в рамках действующего законодательства, опираясь на инициативу и осмысленность наиболее ответственных членов финансового рынка и работников регулирующих органов;

8. Объединение и создание хорошего имиджа. Одним из главных причин увеличения конкурентоспособности российского финансового рынка является формирование его имиджа в глазах отечественных и иностранных инвесторов. Нужно сконцентрировать усилия на том, чтобы побороть предрассудки, которые сохраняются в отношении слаборазвитости российского финансового рынка или отсутствия защиты инвестиций, которые привлекаются на российском рынке. Нужна единая система популяризации информации и знаний о российском финансовом рынке, как среди зарубежных инвесторов, так и внутри страны [3]. То и дело примитивные представления российских предпринимателей о финансовом рынке, склонность некоторых аналитиков и комментаторов шабло- нам иностранных СМИ оборачиваются накоплением безосновательно отрицательных оценок реального положения в Российской Федерации. Невысокий уровень осведомленности граждан, опять же, как и отсутствие доверия к инструментам финансовых рынков приводит к тому, что до сих пор большая доля сбережений населения осуществляется в наличной форме, посредством покупки иностранной валюты и роста объема наличных денег на руках у граждан.

Создание системы информации о финансовом рынке России поможет сформировать объективную картину очевидных возможностей, предоставляемых эмитентам и инвесторам российским фондовым рынком [1].

Решение вышепредствленных задач позволит сформировать достоверную базу долгосрочного роста финансового рынка России и увеличении его роли как в рамках национальной, так и мировой экономики.

В итоге можно сказать, что в минувшие годы были проделаны устойчивые шаги к совершенствованию инфраструктуры рынка и разработке условий для роста, его значимости для исполнения предприятиями своих инвестиционных программ. Все это ведет к тому, что фондовый рынок будет все больше принимать участие в финансировании экономики, особенно если взять в расчет сильное внимание властей к данной проблеме.

Как бы то ни было необходимо отметить, что, невзирая на всю пользу осуществляемых изменений на фондовом рынке России, это не говорит о том, что сразу после того, как все изменения будут исполнены, зарубежные инвесторы мгновенно придут на наш рынок с долгосрочными инвестициями [8]. Чтобы это случилось необходимо кардинально менять российскую экономику, уменьшая ее зависимость от цен на нефть, а также осуществлять эффективную борьбу с коррупцией и уменьшать политические риски в стране. И только тогда приток зарубежных прямых инвестиций в Россию реально будет увеличиваться.

\section{Библиографический список}

1. Андреев П.А., Михайлов А.М. Индикаторы кризиса доверия к финансовым институтам //Проблемы развития предприятий: теория и практика. 2018. № 1. С. 29-32.

2. Васюков Е.А., Жемральский П.К., Михайлов А.М. Анализ инвестиционных стратегий на российском фондовом рынке // Kant. 2018. № 2 (27). С. 246-248. 
3. Коновалова М.Е., Михайлов А.М., Кузьмина О.Ю. Прогнозирование развития фондовых рынков в условиях становления цифровой экономики // Вестник Самарского государственного экономического университета. 2018. № 11. С. 13-19.

4. Михайлов А.М., Патрин С.М. Управление рыночными рисками розничного банка // Вестник Самарского государственного экономического университета. 2015. № 5 (127). С. 104-110.

5. Михайлов А.М., Пономарева М.В. Проблемы и перспективы выхода российских компаний на рынок ценных бумаг // Экономика и социология. 2018. № 37. С. 21-23.

6. Михайлов А.М., Пономарева М.В. Развитие фондовых рынков под воздействием процесса глобализации // Проблемы развития предприятий: теория и практика. 2018. № 1. С. 29-27.

7. Михайлов А.М. Структура иностранных инвестиций в экономику России как отражение интересов иностранных инвесторов // Вестник Самарского государственного экономического университета. 2006. №7. С. 72.

8. Петров Н.А., Абрамов Д.В., Михайлов А. М. Современное состояние институциональной среды региона как фактор, влияющий на отток иностранных инвестиций //Вестник Российского университета дружбы народов. Серия: Экономика. 2018. Т. 26. № 2. С. 283-295.

9. Хансевяров Р.И., Михайлов А.М., Сидюкова А.И. Факторы, влияющие на принятие инвестиционного решения на фондовом рынке //Экономические науки. 2018. № 162. С. 61-67. 